\title{
Identity in transition: an interpretative phenomenological analysis of international humanitarian workers' experiences of returning home
}

\author{
Emilia Marie Wersig ${ }^{*}$ (D) and Kevin Wilson-Smith
}

\begin{abstract}
This interpretative phenomenological analysis explores aid workers' understanding of identity and belonging through the transition from working in humanitarian aid to returning home. Semi-structured interviews were conducted with 10 participants who had returned to the UK after working in recently founded non-governmental organisations in Northern France between 2016 and 2019. Analysis of interview data identified four superordinate themes: (1) shared humanitarian identity, (2) limits and borders, (3) holding on to humanitarian identity and (4) redefining belonging and identity. Aid workers' belonging in humanitarian work settings is rooted in shared moral values and being able to fulfil a clearly defined role. Upon returning, aid workers struggled to reintegrate, manifesting as denial of having left humanitarian work, re-creation of the social setting and moral demarcation. Participants formed a new sense of belonging through redefining their social in-group. The study sheds light on a previously unexplored area of research, specifically characterised through the closeness of the international humanitarian setting and participants' homes. Findings suggest organisations can assist aid workers' re-entry by supporting professional distance in the field, and through opportunities that allow to sustain moral values postmission. Future research should focus on the role of peer support in the re-entry process and the re-entry experiences of aid workers returning from comparable settings further afield (e.g. Greece).
\end{abstract}

Keywords: Humanitarian aid work, Identity, Re-entry, Transition, Interpretative phenomenological analysis (IPA)

\section{Introduction}

\section{The situation in Northern France}

With more displaced individuals coming to and across European borders in recent years, inadequate provision of housing and resources have led to the establishment of makeshift camps (Davies et al. 2017; UNHCR 2018). The border region of Northern France has become a focal point for such sites, where displaced individuals are supported by humanitarian workers (Davies et al. 2017; MSF 2016a). This research focuses on the identity of

\footnotetext{
* Correspondence: emilia.wersig@gmail.com

School of Psychology, University of Glasgow, 62 Hillhead Street, Glasgow G12
} $8 \mathrm{QB}, \mathrm{UK}$

Springer Open these workers through the transition from working in humanitarian aid to returning home.

Although camps, often referred to as 'Jungles', have existed in Northern France since the late 1990s, their populations dramatically increased after 2014, as more displaced individuals have attempted to reach the UK or await the outcome of asylum processes in France (Dhesi et al. 2018; McGee and Pelham 2018; Sanyal 2017). In response, the French and British governments deployed high numbers of police and reinforced border security (Joint Ministerial Declaration 2015). French authorities refuse to recognise sites as official refugee camps, avoiding an obligation to provide support in accordance with the United Nations High Commissioner for Refugees'

(c) The Author(s). 2021 Open Access This article is licensed under a Creative Commons Attribution 4.0 International License, which permits use, sharing, adaptation, distribution and reproduction in any medium or format, as long as you give appropriate credit to the original author(s) and the source, provide a link to the Creative Commons licence, and indicate if changes were made. The images or other third party material in this article are included in the article's Creative Commons licence, unless indicated otherwise in a credit line to the material. If material is not included in the article's Creative Commons licence and your intended use is not permitted by statutory regulation or exceeds the permitted use, you will need to obtain permission directly from the copyright holder. To view a copy of this licence, visit http://creativecommons.org/licenses/by/4.0/. 
(UNHCR) guidelines, and limiting access for governmental aid organisations (Agier et al. 2019; Dhesi et al. 2018; McGee and Pelham 2018; MSF 2016b).

Humanitarian needs in Northern France include lack of shelter, limited access to water, poor sanitary conditions, medical issues and lack of provision for separated and unaccompanied minors (MSF 2016a; 2016b; OHCHR 2017, 2018; UNHCR 2016). The situation is further characterised by criminalisation and disruption of aid provision, and reports of violence at the hands of French authorities (Agier et al. 2019; Amnesty International 2019; Human Rights Watch 2017; McGee and Pelham 2018). Other challenges are the presence of smuggling networks and violence (Agier et al. 2019; Joint Ministerial Declaration 2015; Sandri 2018).

To address these needs, and the absence of governmental support, non-governmental organisations (NGOs) provide humanitarian assistance. Wellestablished NGOs, including Médecins Sans Frontières (MSF) and the French Red Cross, work alongside organisations founded in response to the situation (Dhesi et al. 2018; McGee and Pelham 2018). The latter are often still in their infancy and operate with little organisational protocol and training, setting their work structures apart from those of more established organisations (Agier et al. 2019; Sandri 2018).

Aid in Northern France is mostly provided on a voluntary basis, by individuals untrained in humanitarian work, as is common in humanitarian NGOs (Reis and Bernath 2016; Sandri 2018). Though the majority of volunteers are providing aid relatively close to their home country (UK), they are acting as international humanitarian workers (Agier et al. 2019; Sandri 2018). Their work includes providing access to food and water, clothing, sanitary supplies and shelter, as well as support for children, unaccompanied minors and women (McGee and Pelham 2018; Sandri 2018). Living in Northern France for extended periods of time, their experiences are also shaped by 'sociality' (Sandri 2018, p. 67), the creation of new social spaces, where community and friendships are formed (Agier et al. 2019).

\section{Challenges experienced by humanitarian workers}

Research identifies a lack of resources, long working hours in stressful, high-pressure environments and exposure to traumatic events (primary and vicarious) as challenges which can impact aid workers' mental and physical health-leading to anxiety, depression and posttraumatic stress disorder (Ehrenreich and Elliott 2004; Jachens et al. 2018, 2019; McCormack et al. 2009; Strohmeier and Scholte 2015). The majority of humanitarian work is carried out away from aid workers' homes and support networks (Ehrenreich and Elliott 2004; Eriksson et al. 2009; Jachens et al. 2019; Snelling 2018;
Wartenweiler and Eiroa-Orosa 2016). Thus, many workers experience social isolation, despite being part of a community of co-workers (Jachens et al. 2018, 2019; McCormack and Joseph 2013).

Aid workers operate in a complex social setting during missions, where boundaries between work and personal life dissolve due to factors including shared living spaces with colleagues, lack of privacy and flexible working hours (Hunt 2010; Jachens et al. 2018, 2019; McCormack et al. 2009). Returning from humanitarian work commonly includes difficulties with social reintegration, disorientation and withdrawal (McCormack and Joseph 2013; McCormack et al. 2009; Snelling 2018).

\section{Theoretical framework}

A seminal approach for understanding the experiences of social belonging in the re-entry process of humanitarian workers can be social identity theory (SIT) (Tajfel 1978, 1982; Tajfel and Turner 1979; Turner 1975; Turner and Brown 1978). SIT provides a framework for understanding the identity and belonging experienced by individuals as part of groups of people. Two sociocognitive processes are thought to underlie the formation of social identity: categorisation and selfenhancement (Tajfel 1982). Categorisation is the cognitive function that organises a person's social environment, assigning individuals to social groups and according attributes. Self-enhancement is the striving of individuals to maintain or enhance their self-esteem, including through the superiority of their group (in-group) over other groups (out-groups) (Tajfel 1982). Belonging to a group is thus descriptive of a member's selfconcept, prescriptive of the according behaviour and also evaluative, in that it encourages comparison to outgroups (Hogg et al. 1995).

Turner further developed aspects of SIT in selfcategorisation theory (SCT), which elaborates on the process of categorisation and postulates that similarities with the in-group, and differences with the out-group, are accentuated in the formation of group-identity (Turner and Reynolds 2012). Here, people are depersonalised: they take on the group's identity prototype, are perceived and act as members of the group, leading to group cohesion, shared attitudes, beliefs, norms and behaviour (Hogg et al. 1995). Notably, group-identity is not fixed, but dynamic in response to the social context and which groups are salient (Turner et al. 1994; Turner and Reynolds 2012).

Applied to the lived experience of humanitarian workers, SIT and SCT suggest that aid workers belong to the social category of 'humanitarian worker', and that this category will be entered, enhanced and salient in the context of humanitarian aid. However, in the process of re-entry, humanitarian workers will be confronted with a 
loss of the in-group. This implies that re-entry is likely to affect aid workers' identity and self-concept, including attitudes, behaviour, beliefs and norms.

\section{Research on re-entry from humanitarian work}

Only a fraction of the literature on humanitarian work focuses on aid workers' re-entry process (Hearns and Deeny 2007), with quantitative research addressing mental health (Eriksson et al. 2001) and organisational support (Ehrenreich and Elliott 2004). Much work is qualitative, reflecting the diverse and individual nature of aid workers' experiences (Hunt 2008). Research identifies aid workers' moral identity-comprised of moral values and the willingness to take losses to their personal lives to realise these-as the main motivator in undertaking assignments (Fechter 2012; Hunt 2008; McCormack and Bamforth 2019). Whilst aid workers aim to realise their values in the work, it is a morally complex environment, where expectations of what one can achieve often fail to match reality under financial, organisational and policy constraints (Chouliaraki 2013; Hunt $2008,2010)$. When aid workers are unable to relieve suffering or save lives, this leads to issues around their identity as humanitarian workers (Hunt 2008, 2010). Here, failure to actualise values may inhibit fulfilment of the group's identity prototype and self-enhancement through comparison to out-groups.

For aid workers in McCormack and Joseph's (2013) research, values pre-mission could not be aligned with the lived experience of humanitarian work. Confronted with losing parts of their former identity, participants withdrew from family and community. Research with Christian humanitarian workers identified equivalent moral and social challenges upon re-entry (Selby et al. 2009; Wartenweiler and Eiroa-Orosa 2016). However, aid workers were able to overcome feelings of social isolation and loss by redefining their identity (McCormack and Joseph 2013; Wartenweiler and Eiroa-Orosa 2016). Here, adjusting their belief and value systems allowed aid workers to bring pre- and post-mission identities into harmony, experience a reparation of self and move forward in their lives. Thus, humanitarian workers were understood to undertake a 'social journey from belonging to re-orientation' (Wartenweiler and Eiroa-Orosa 2016, p. 180).

Altruistic identity disruption (AID) is a construct describing the re-entry process, characterised by interrelated feelings of isolation, doubt and self-blame' (McCormack et al. 2016, p. 2). Experiencing AID, humanitarian workers struggle to reintegrate socially and question their identity as aid workers (McCormack and Joseph 2012; McCormack et al. 2016). The experience of isolation encourages them to draw on peer support and return to the field swiftly, re-entering a social setting with others who share their experiences (McCormack et al. 2009). Aid work is described as a 'bubble' (Snelling 2018, p. 11), an addictive setting to return to (McCormack et al. 2009; Snelling 2018). Relationships with other aid workers are experienced as satisfying, whilst 'people outside the group don't understand' (aid worker, cited in McCormack et al. 2009, p. 113).

\section{The puzzle of identity in transition}

This research explores the lived experience of aid workers who have returned to the UK after providing assistance in Northern France, focussing on their understanding of group membership and identity in the process of leaving humanitarian work and returning home. The literature on re-entry from aid work is fragmented (Hearns and Deeny 2007; Szkudlarek 2010), and future work should aim to incorporate 'psychological, cultural and socio-political aspects of re-entry' (Szkudlarek 2010, p. 12). Furthermore, research is needed to capture the current and highly diverse experiences of humanitarian workers (Eriksson et al. 2001; Hunt 2008). With re-entry being a major challenge, this research has real-life relevance in generating a better understanding of humanitarian workers' lived experience, needed to provide adequate support (Hunt 2008; McCormack et al. 2009; Wartenweiler and Eiroa-Orosa 2016). Researching the experiences of those providing humanitarian assistance in Northern France is of particular relevance as it is a recent, on-going situation, with few studies to date. Existing research is mostly anthropological in nature, tends to cover the 'Calais Jungle', not the situation across Northern France, and focuses on the period until October 2016. Furthermore, it is a distinct humanitarian work setting: The majority of aid workers are young, without prior experience in humanitarian work, and whilst acting as international humanitarian workers, they operate relatively close to home (UK) (McGee and Pelham 2018; Sandri 2018).

This research builds on the lived experience of 10 individuals who provided humanitarian assistance with recently founded NGOs in Northern France between July 2016 and May 2019. The study is explorative in nature, aiming to provide a platform for individual aid-workers' sense-making and form an understanding of their experiences sensitive to their socio-cultural reality.

\section{Method}

\section{Interpretative phenomenological analysis}

The study is carried out following the guidelines of interpretative phenomenological analysis (IPA), a qualitative research method used to capture and understand how people make sense of their lived experience (Smith et al. 2009). IPA's roots lie in phenomenological philosophy, which understands phenomena of the world as not 
accessible directly, but only through lived experience ('Erfahrung') (Husserl 1913, 1970). However, as experience takes place in the context of 'meaning and value (...), needs, interests, (...) and so on' (Edie 1987, p. 19), one needs to step outside these attitudes to understand objects in their own right (Smith et al. 2009). Husserl (1913) suggests that this becomes possible through the method of 'epoché'-or bracketing-which refers to putting aside one's knowledge, prejudices and taken-forgranted ideas about the world to allow actual perception of the world to take place. Through this process of reduction, the essential qualities and meaning of an object can emerge, which transcend the particular and make it accessible in a general way (Smith et al. 2009).

Heidegger further developed phenomenology by taking an existential turn, rejecting the idea of 'epoché', and instead recognising an individual, interpretative stance or viewpoint as the necessary condition for knowledge and the creation of meaning (Smith et al. 2009). Heidegger recognised the observer of experience as part of the world, and their way of seeing and understanding the world as shaped by it (Langdridge 2007). Hence, experience cannot be merely described, but must be interpreted within its context (Smith et al. 2009). This is the reason interpretative phenomenology is also referred to as hermeneutic-concerned with the uncovering of knowledge through interpretation (Heidegger 1977).

Building on these concepts, Smith (1996) developed IPA to research the lived experience of individuals and how they make sense of it. The focus of IPA is on the particular and detail, not the generalisation of findings, making it idiographic in nature (Smith and Osborn 2013). This distinguishes this qualitative method from the objectives of quantitative research; samples are small and purposive (Smith et al. 2009). As IPA recognises any understanding of another person as necessarily interpretative, it utilises a double hermeneutic where the researcher is trying to make sense of the participants trying to make sense of their world' (Smith and Osborn 2013, p. 26).

\section{Rationale for methodological choice}

As this research aims to explore and understand aid workers' experiences of identity and belonging in the process of leaving humanitarian aid and returning home, it is congruent with a phenomenological perspective. IPA is appropriate for researching complex, or previously unexplored phenomena and is insightful for experiences that have affected or changed people's lives (Smith 1996; Smith and Osborn 2013). For instance, IPA has been recognised as a useful method in research on personal and cultural identity (Reid et al. 2005). In the present study, IPA was used instead of descriptive phenomenological analysis, as an interpretative approach allows insights into how participants make sense of their experiences of belonging and identity (Lopez and Willis 2004). As IPA is particularly sensitive to the context of participants' meaning making (Lopez and Willis 2004), it allows understanding of the process of leaving the humanitarian setting and returning to the UK. Lastly, IPA emphasises expert knowledge as a useful starting point for enquiry into a subject area (Lopez and Willis 2004) and is thus congruent with the lead researcher's subject position.

\section{Data collection and participants}

Ten semi-structured face-to-face interviews (in person $(n=5)$ or using video call $(n=5)$ where travel was not possible for participants) took place between January and June 2019. The research was advertised through a UK-based network for those currently and formerly active in humanitarian work in Northern France. Participants were required to (1) be adults aged 18 years or above, (2) be fluent in English, (3) have worked in humanitarian aid in Northern France and (4) have returned to the UK within the last 18 months and for a minimum of 1 month. Ten participants-five male, four female, one non-binary-met the inclusion criteria; their names have been replaced by pseudonyms to preserve confidentiality; all had worked with recently established NGOs (Table 1).

\section{Procedure}

The semi-structured interview schedule included nine questions, with flexible follow-ups and prompts. Funnelling was used to encourage participants to make sense of their experiences (Langdridge 2007; Smith and Osborn 2013). This interview technique moves from broad questions, aiding participants' memory recall, towards more specific questions in areas of particular interest (Noon 2018; Smith and Osborn 2013). Interviews lasted between 27 and 89 min (mean $=58.8$ ) and were voicerecorded. Each interview was transcribed after data collection and before proceeding with subsequent interviews, as suggested by Smith et al. (2009). The lead researcher transcribed data verbatim after two rounds of initial listening. The stages of analysis follow Smith et al. (2009, pp. 79-107):

(1) The researcher read the transcript once whilst listening to the audio recording and then re-read it numerous times, to enter the world of the participant. (2) After the second reading, the researcher began to note initial exploratory thoughts and comments throughout the transcript, going line by line. These included descriptive comments, such as noting the participant's key phrases and words, comments on the use of language, and conceptual comments and questions arising from the transcript. (3) The researcher then shifted the focus on these 
Table 1 Participants

\begin{tabular}{llll}
\hline Pseudonym & $\begin{array}{l}\text { Age } \\
\text { range }\end{array}$ & $\begin{array}{l}\text { Months spent working in humanitarian } \\
\text { aid (range) }\end{array}$ & $\begin{array}{l}\text { Months spent in the UK after returning from Northern France (at } \\
\text { point of interview) }\end{array}$ \\
\hline Anna & $21-25$ & $6-10$ & 12 \\
Ben & $21-25$ & $11-15$ & 1.5 \\
Charlie & $21-25$ & $6-10$ & 10 \\
Daniel & $26-30$ & $16-20$ & 18 \\
Jess & $31-35$ & $11-15$ & 7 \\
Katy & $21-25$ & $1-5$ & 2 \\
Martin & $26-30$ & $16-20$ & 2 \\
Paul & $36-40$ & $11-15$ & 7 \\
Sarah & $21-25$ & $1-5$ & 12 \\
Tom & $21-25$ & $11-15$ & 9 \\
\hline
\end{tabular}

initial notes, working in chunks to understand what was of importance in each part of the transcript, condensing these aspects into a short phrase, referred to as a subordinate theme. (4) Thereafter, the researcher mapped connections between themes to capture a participant's sense-making. This process included clustering related themes and finding a short phrase that describes them as an overarching, superordinate theme. The relationship between themes, their contextual elements, function and frequency was also examined. (5) The researcher then repeated all previous stages with each subsequent transcript, remaining open to the individual sense-making of each participant. (6) Finally, the researcher looked for connections and differences across all cases, and developed a table of themes.

The analysis of data (stages 2-5) and decision of final themes (stage 6) involved robust discussions between both researchers, with the second author taking a supervisory role. Throughout the stages of analysis, themes were re-checked against the data by both authors to prevent the analysis from shifting into the researchers' world (Smith 1996). Theory was only used explicitly after the final table of themes had been developed.

\section{Reflexivity}

In line with the interpretative phenomenological approach of the research, the researchers acknowledge their impact on the study. In order to be transparent as to how personal experiences and dispositions may have affected the research, a reflexive journal following Langdridge (2007) was kept.

The lead researcher has experience of working in humanitarian aid in Northern France; her interest in the phenomenon of returning home led her to pursue this study. Seven participants were familiar with the lead researcher through this setting, and all were aware she had worked in Northern France. The lead researcher perceived no hierarchy between herself and participants, as neither work in the setting anymore and previously did so at an equal status. Participants perceived the researcher as an insider, apparent through the use of insider language. Familiarity with the situation likely made the interview process less intrusive, given that the lived experience was described as difficult to speak about to outsiders. The personal connection to humanitarian work gave credibility to the researcher's intentions and allowed access to the participants. This is relevant as participants' work in Northern France has encountered negative media attention and has at times been criminalised (Amnesty International 2019; Human Rights Watch 2017)

Whilst IPA recognises the role the researcher plays in co-creating knowledge (Langdridge 2007; Smith and Osborn 2013), this comes with the danger of misinterpreting data. The lead researcher understands that her subject position may influence the analysis by unintentionally shifting sense-making towards her personal experiences or expectations. The second author has no experience of working in humanitarian aid in Northern France. Throughout the analysis, both researchers engaged closely and sensitively with the data and participants' individual life contexts to stay true to their sensemaking (Larkin et al. 2006; Reid et al. 2005).

\section{Analysis \\ Analytical overview}

The analysis found four superordinate themes, and associated subordinate themes, as detailed in Table 2.

Themes were chosen on the basis of being particularly prevalent or emphasised in participants' accounts, being striking, novel or relating to each other in noteworthy ways. They were identified in the accounts of five to eight participants, with the exception of themes $2 b$ (three accounts) and 3c (four accounts). Interpretations are supported by data extracts, selected to represent themes. In the quotations that follow, square brackets 
Table 2 Overview of themes

\begin{tabular}{ll}
\hline Superordinate theme & Associated subordinate themes \\
\hline 1. Shared humanitarian identity & $\begin{array}{l}\text { a.Moral values drive humanitarian action } \\
\text { b.Having a role and being good at it }\end{array}$ \\
$\begin{array}{ll}\text { 2. Limits and borders } & \text { a.Going to the limit } \\
& \text { b.Crossing the border } \\
\text { 3. Holding on to humanitarian identity } & \text { a.Denial } \\
& \text { b.Re-creation of the social setting } \\
\text { c. Redefining belonging and identity } & -\end{array}$ \\
\hline
\end{tabular}

indicate non-verbal language, dashes indicate words left unfinished by participants, ellipses indicate where nonrelevant material has been omitted and words within ellipses indicate where content has been replaced for anonymity, or added for clarification.

\section{Superordinate theme 1: shared humanitarian identity}

This superordinate theme captures the identity and belonging experienced whilst working in humanitarian aid. Participants understood the intersection of shared values and having a clearly defined role as creating, sustaining and enhancing their belonging in humanitarian work, leading to a shared humanitarian identity. The subordinate themes are (a) moral values drive humanitarian action and (b) having a role and being good at it.

\section{Subordinate theme 1a: moral values drive humanitarian action}

Participants reflected on their moral values as the driving factor that led them to work in Northern France, a setting where these values could be put into action:

I feel like I'm meant for something else (...) living a life, ahem, in which I, yeah, I contribute to the world, and, and my part (...) I've always felt that being purposeful is what kind of guides me and drives me (...) I really, I really couldn't imagine me doing any other roles, where, where I'm not trying to support or help other people. So I think that is, it's a value (Jess: 155-182)

Jess's account invokes an idea of destiny, highlighting to help others as an essential aspect of her identity. She understands it as her 'part', suggesting that there is a specific role for her to take and fill, which indicates that to realise her sense of self she needs to do this kind of work. Being in a setting with other aid workers who likewise strive to put values into action created strong ingroup cohesion:

I think there is something hugely to be said as well, when you're working with a lot of people, both from Calais and Dunkirk, who share, you know, there's that assumed base-rate of shared values (...) and you immediately feel a sense of belonging (Katy: 162-169)

Interestingly, Katy uses the word 'base-rate' to describe the values those working in humanitarian aid are assumed to share, suggesting a benchmark that is expected of aid workers. Passing the standard creates immediate belonging, which arises as these values form an essential part of the humanitarian identity. Helping or supporting others and responding to a humanitarian need were identified as core values across interviews, defining the shared identity prototype that aid workers acted-and were expected to act-upon. Interestingly, participants reflected on their values as setting them apart from others providing assistance to the same group of aid beneficiaries, e.g. local emergency services, which suggests the importance of an underlying humanitarian motivation, in addition to wanting to help others.

\section{Subordinate theme 16 : having a role and being good at it}

This theme describes the importance of having a clearly defined place and responsibilities in humanitarian work, and filling that role successfully, to create belonging. Ben comments on being able to use his personality and skills in a valuable way:

It definitely made me feel like I had a purpose and a job to do, and actually like having confidence in yourself to be able to do that job well was very important in the whole belonging thing, so like, eh, going out and leading distributions, and making friends, and talking to people, that's, like I've always been a very sociable person, and this was like a time that I could put that to use in a situation that actually felt like it was doing something positive, instead of just talking to people over a bar, or something like that (Ben: 281-292)

Ben's account suggests that through working in humanitarian aid, who he understands himself to be and what he needed to do aligned, with his identity fitting the humanitarian role. He reflects on 'confidence', 
suggesting that he received positive feedback on his role execution from peers. Remarking on the positive meaning of his work in Northern France, Ben contrasts his experience of humanitarian with non-humanitarian work settings. Daniel remarks:

Everybody (...) trusted each other, and expected each other to make the right decisions (Daniel: 4952)

The importance Daniel places on expectations and trust in belonging to the group of humanitarian workers suggests that the work allowed aid workers to re-affirm and receive positive feedback on their belonging, enhancing their shared identity as humanitarian workers. Likewise, it implies there are wrong decisions, and that people who would make them would not belong.

\section{Superordinate theme 2: limits and borders}

This superordinate theme discusses what led participants to leave Northern France and return to the UK, as well as the experience of passing the border. Subordinate themes are (a) going to the limit and (b) crossing the border.

\section{Subordinate theme 2a: going to the limit}

Participants understood the continuous challenges experienced in their work, eventually reaching a point where they felt they had done everything they could and had nothing more to contribute, as leading them to leave Northern France:

And I hit that breaking point in me, was exhausted. (...) I think it was, just not meant to be here anymore. Ahem, I've done as much as I can. Eh, I've given as much as I can. I don't have anything left to give. I think that was the big thing. I got nothing left to give. I've literally emptied myself and given everything I have. And now there's nothing left. (Jess: 258-284)

Jess vividly describes reaching a 'breaking point' and not being able to go on, suggesting an internal struggle between her values and humanitarian motivations, and the feeling of burnout she invokes. Strikingly, she recalls feeling herself not 'meant to be' in the humanitarian aid setting anymore, which stands in direct contrast to the calling she felt to work in Northern France. Jess emphasises the idea of having 'emptied' herself, which suggests that with not being able to continue the work, and realise her role of helping others, there is a loss of her purpose and part of who she understands herself to be. Katy reflects:
You're, you're basically a foot solider on the ground, and it's just 'Okay, we need your fresh energy, we need everything you got', and then you give everything, and then you just leave. (Katy: 256-260)

Using the analogy of 'a foot solider' to describe her experiences, Katy invokes the idea of battle, capturing the relentless, on-going and overwhelming challenges she faced in humanitarian work, described as part of her interview. It further suggests she felt like she was doing hard front-line work, whilst having no power over deciding what she did or the greater picture. This is particularly interesting as participants reflected on the often improvised nature of their work, with organisations providing few indications of future directions. Katy's emphasis on the work as being more important than her and losing her place once she could no longer contribute, links in well with other accounts. Participants' reflections on belonging suggest merely holding values is not enough to identify as humanitarian workers, but that values need to be realised through humanitarian action.

Across interviews, participants reflected on the process of leaving their work with recently established NGOs. There were little to no organisational structures in place to support their return to the UK, with debriefing only taking place for few participants. There was a strong emphasis on wanting to focus on the work itself, and participants expressed their own reluctance to engage with preparations for their return (e.g. unwillingness to set a leaving date, not booking travel, making no preparations for their arrival in the UK).

\section{Subordinate theme $2 b$ : crossing the border}

Leaving Northern France and crossing the border to the UK carried symbolic value for participants, as in their work they supported displaced individuals who were attempting to cross the border legally or illegally. The symbolic nature of the border is captured by image-rich descriptions of the crossing of the border:

Passing back through that border as well was quite a [Pause], probably like the most visceral feeling I felt, and I almost, I couldn't, and I like had that weird hallucination where I like looked at the border, and it felt like it was just dripped all over with blood. (Katy: 310-315)

Katy's description of the border passage suggests that she experienced a deep-seated, physical, intuitive reaction to being in the border-space. Her use of the word 'hallucination', which goes beyond imagination or thought, highlights the strength of her experience. Katy's description further suggests a strong association of the 
border with the struggle, injuries and loss of life of displaced individuals, which aid workers in Northern France encounter. The border may also be a symbolic representation of French and British border policy, which shapes the border space of Northern France, with dripped blood representing the hurt the border causes. Crossing the border takes a central role in the personal journey of participants, as it represents them leaving humanitarian work, where they experienced belonging and shared identity. Entering separate lives in the UK, an identity border is crossed; thus, other identities will be activated and may be(come) more salient for participants.

\section{Superordinate theme 3: holding on to humanitarian identity}

This superordinate theme discusses participants' experiences after returning to the UK, shaped by trying to hold on to the belonging and identity they had experienced in humanitarian work and struggling to reintegrate into their former lives in the UK. The subordinate themes are (a) denial, (b) re-creation of the social setting and (c) moral superiority.

\section{Subordinate theme 3a: denial}

This subordinate theme captures participants not fully processing that they returned to the UK permanently, instead feeling they were visiting:

I arrived in the UK, but it all felt quite like a blur, like I was on holiday (...) part of me always thought like "Oh, I'm just gonna go back and, back to my normal life, which is continuously working, and that warehouse, and distributing aid”. (Charlie: 776-794)

Charlie's account suggests it was difficult to make sense of the experience of returning home and it may have felt confusing and overwhelming. The comparison to a 'holiday' represents how it felt temporary, not having accepted or processed that they had really left humanitarian work. The life in Northern France is described as their 'normal life', suggesting humanitarian work had become Charlie's daily reality, replacing their former normal life in the UK, highlighting the fluid nature of identity. Charlie's reaction upon returning indicates the humanitarian identity is most salient.

\section{Subordinate theme $3 b$ : re-creation of the social setting}

In response to the loss of the humanitarian work setting, participants re-created the social setting by drawing strongly on peer-support from others who have returned to the UK. Martin reflects on spending his time upon returning with former co-workers:
Being, staying at theirs (...) made me not feel as isolated (...) I was pretty much with them the whole time, except when they were going to work, and even then, I would sometimes be at their work, but that's basically Calais, really [Laughs]. (Martin: 693699)

Martin's description highlights his heavy reliance on being around his former co-workers to not feel 'as isolated' upon returning home. This implies he experienced social isolation and a lack of belonging upon returning. Martin jokingly compares being around his former coworkers as being 'basically Calais', suggesting he is aware he is re-creating the social belonging he experienced in humanitarian work. Anna similarly reflects:

I'd probably like to live, like, with some people from Calais. (...) I want to live in like a flat with like six people in it [Laughs], so like the caravan (in Calais).

(Anna: 526-534)

Anna wants to re-create her experience of the shared living space with other workers in humanitarian aid, indicating her longing for the social setting she left behind. Her laughter may intend to show she is aware that wanting things to be like in Calais may appear strange. These accounts capture participants' struggle to hold on to their humanitarian identity by trying to maintain belonging with a now physically distant group.

\section{Subordinate theme 3c: moral superiority}

Upon returning to the UK, participants experienced feelings of moral separation between themselves and others, who had not been active in humanitarian aid:

I just like felt really like mean, I just felt like morally superior, I just felt like I was looking at people, like "Why (...) are you not doing anything?". (Anna: 273-278)

Anna's description of herself is akin to an observer, which indicates her search for similarities and dissimilarities between herself and those around her in the UK. Anna suggests a distance between her own values and the values and actions of those she encounters upon returning home. The feeling of superiority indicates Anna perceived her own values as right. However, she describes feeling 'mean', which implies she perceived herself as judgmental. Anna appears to express a struggle between different identities. These are her former self, which may have made similar choices, thus feeling bad about her judgment, and her humanitarian identity, the salience of which enhanced the importance of moral values and actions. 
Superordinate theme 4: redefining belonging and identity The final superordinate theme discusses participants' processes of moving forward in their lives in the UK, which was possible through redefining their belonging and identity, adjusting their actions and choices. For Paul, this meant amending his expectations about work:

I'm gonna have to make some kind of like concessions I suppose, if that's the right word, to, to how things are. (Paul: 951-954)

Whilst he expressed a strong identification with the non-corporate environment of Calais, Paul recognised the need to reintegrate into work life in the UK. The use of 'concessions' implies having to give up on some expectations, values or wishes in order to move forward. Crucially, as upholding these elements defined his social group in Northern-France, this can be understood as a challenging transition into a previously devalued group. Daniel reflects on trying to engage with what is meaningful to him outside of work:

To get this feeling of like value back (...) you do all the other stuff that you feel makes you a person, outside of that, like squeezing it all in, like doing social stuff, volunteering (Daniel: 451-455)

For Daniel, doing 'social stuff, volunteering' seems a take a similar role to the humanitarian work he was doing in Northern France-allowing him to realise his idea of who he is. 'Squeezing it all in' illustrates Daniel's attempt to bring different, possibly conflicting parts of his life together. Thus, it seems Daniel is entering an identity that allows him to bridge the gap between his humanitarian belonging and life in the UK. Importantly, for Daniel and other participants, simply going back to their old life did not suffice to sustain the values realised in the humanitarian setting-they appear intricately tied to humanitarian action. Charlie found new belonging through working with local organisations supporting asylum-seekers:

Doing that has helped me feel like I belong here, cos I don't feel like I, I have left it behind fully, but that I'm able to have a life outside it (...) that has been a way in which I felt like I can help, but without giving up things. (...) I feel like I can do other things that I love doing. (Charlie: 914-936)

Charlie describes finding belonging and living their values by supporting UK-based asylum-seekers upon returning home. Working with people that share lived experience with, and include, former aid beneficiaries from Northern France, Charlie is able to build a connection between their humanitarian identity and their life in the UK. Charlie's account suggests an ongoing identification with their humanitarian peer-group, which they may have extended to include the social setting of their new work with asylum-seekers. Yet, the use of 'a life outside' indicates that Charlie does belong to more than one social group. Living in the UK, Charlie appears to realise different parts of their social identity and to bring together their diverse lived experience.

\section{Discussion}

This research explores aid workers' lived experiences of belonging and identity, and how these are understood in the transition from humanitarian work to returning home. It focuses on UK-based humanitarian workers, who were active with recently established NGOs in Northern France. The analysis identifies four superordinate themes, exploring how aid workers make sense of their identity and the social journey from belonging in humanitarian aid, through the challenges of re-entry, to redefined belonging and identity (Fig. 1). Participants do not believe they have reached the end of their identity transition; they reflect on their identity development as on-going. The developed themes follow the chronological timeline of aid workers' lived experience, as well as representing the stages of their physical journey from Northern France to the UK; they are discussed in turn below.

Working in humanitarian aid, participants experienced a strong sense of belonging with peers, captured in the first superordinate theme (1) 'shared humanitarian identity'. They made sense of this belonging through shared moral values, and successfully filling a defined role as an aid worker. The first subordinate theme (1a) 'moral values drive humanitarian action' aligns with studies on

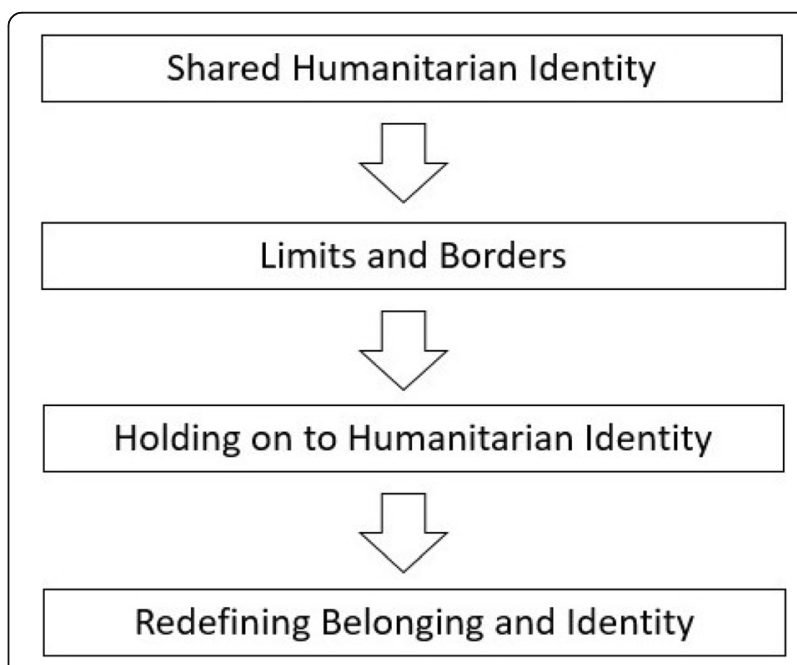

Fig. 1 Humanitarian workers' understanding of belonging and identity in the transition from humanitarian work to returning home 
the role of moral values in humanitarian work (Fechter 2012; Hunt 2008, 2010; McCormack and Bamforth 2019). Research understands aid work as a way to integrate personal values and work, allowing humanitarian workers to realise their identity by being active in humanitarian aid.

Participants of the present study suggested that there is a minimum standard of values expected of aid workers, fulfilment of which constituted a shared group identity. This suggests a socio-cognitive process of categorisation, dividing people into in- and out-groups. The moral values participants discussed were broad categories (helping others, responding to humanitarian needs). This focus on general, humanitarian characteristics, instead of personal background or other features of their peers, suggests these values are accentuated in humanitarian work, enhancing in-group identity. These processes map well onto SIT and SCT (Hogg and Terry 2000; Hogg et al. 1995; Tajfel 1982; Tajfel and Turner 1979), with aid workers' fulfilment of the group's moral value prototype creating belonging.

The second subordinate theme (1b) 'having a role and being good at it' expresses participants' successful fulfilment of their roles and how they understood this as creating belonging. With NGOs in Northern France providing a diverse range of assistance, participants were able to find a place where they felt useful-often outside their educational or professional background. Here, they received confirmation of their successful role fulfilment from peers, enhancing their belonging with the in-group.

This contrasts with experiences of humanitarian workers who, unlike participants in the current study, provide health and medical assistance (Hunt 2008, 2010; McCormack and Joseph 2013). They reflect on frustration and regret, as well as self-doubt regarding their ability to contribute. Underlying this difference may be the nature of the work; participants of these studies entered humanitarian work with specific workplace and role expectations due to their professional background and training. These often failed to match working conditions and responsibilities in the field. Interestingly, research suggests role clarity and performance play an essential part in the retention of humanitarian workers (Dubey et al. 2016). The current findings raise the question whether social belonging may be a mediating factor in the relationship between role clarity/performance and retention. With retention being a major challenge faced by NGOs (Korff et al. 2015), the current study also raises the question whether retention may differ according to the (professional) role expectations workers hold when entering humanitarian work.

Having contributed as much as they felt able to, participants reflected on no longer having a place in humanitarian work and leaving Northern France, captured in the superordinate theme (2) 'limits and borders'. The experiences discussed in the first subordinate theme, (2a) 'going to the limit', demonstrate how participants ceased to fulfil the in-group's identity prototype, driving them to leave. Participants' accounts highlight the importance of putting values in action for their belonging as humanitarian workers, suggesting participants' selfconcept and belonging to the in-group are challenged when they can no longer take humanitarian action, as they cease to fulfil the group's identity prototype. Having reached a 'breaking point', participants described a similar struggle to that identified by Hunt's $(2008,2010)$ research, wherein workers, when unable to perform their role identities, e.g. relieve suffering or save lives, found their identity as humanitarian workers challenged. Contrasting with the current study, this was not directly related to leaving the field, but understood as one of the many challenges faced in humanitarian work. This difference could be related to professional background; whilst Hunt's $(2008,2010)$ research focuses on health professionals, for the majority of participants in the present study prior professional training did not match their work in Northern France.

Across accounts, participants reflected on an absence of organisational structures that would have prepared them for leaving the humanitarian work setting; instead, most participants left abruptly, unprepared for their return to the UK. Participants made sense of their lack of preparation as wanting to focus on their work. Belonging with the humanitarian in-group depended on being able to take humanitarian action. Thus, avoiding preparing for their return home may also have allowed participants to sustain belonging with the humanitarian in-group.

Physically leaving Northern France involved (2b) 'crossing the border', the second subordinate theme. Participants' experiences are similar to those in McCormack and Joseph's (2013) research, which described aid workers' physical journeys as the crossing point into their former lives, including its social context. However, with border policies shaping the nature of the humanitarian work in Northern France, the border becomes a physical representation of participants' experiences in aid work. Here, image-rich descriptions of the border crossing indicate the meaning it takes in the sociopolitical context of participants' lived experience. The situation is closer to their homes than other international humanitarian settings tend to be, politically (i.e. with the involvement of the UK government in border policy), physically (i.e. journey time) and culturally. This may explain why previous research does not address international aid workers' return journeys in-depth; the passing of physical space has a different significance within the current context. Research on social identity and representations of the physical world suggests 
identity threats alter how individuals perceive physical distances (Xiao and van Bavel 2012). Applied to the current study, this raises the question of whether the threat to participants' identity through loss of the humanitarian in-group after leaving Northern France shapes their perceptions of the border space.

Upon returning, participants sustained humanitarian belonging by (3) 'holding on to (their) humanitarian identity', the third superordinate theme. (3a) 'Denial', the first subordinate theme, describes participants' confusion and feeling they had only temporarily returned to the UK, with Northern France understood as their 'normal life'. Here, denying they had left the humanitarian work setting for good, participants were able to hold on to their in-group. Whilst previous research addresses the swift return to the field, this is considered in regard to the social isolation experienced upon re-entry (McCormack and Joseph 2013; McCormack et al. 2009). To the researchers' knowledge, there are no accounts of denial in the literature. A potential explanation for this difference may be the roles filled in Northern France. As aid workers here operate mainly outside their educational or professional background, they may have kept fewer professional boundaries in their roles compared to health and medical professionals, who are aiming to maintain their professional identity whilst working in humanitarian settings (Hunt 2008). Furthermore, working for recently founded organisations that operate with few protocols on how specific work is to be carried out (e.g. development and maintenance of professional boundaries with beneficiaries), aid workers' personal lives and work may have converged more strongly than in other settings, increasing the salience of their humanitarian identity.

Aid workers expressed their values, i.e. helping or supporting others and responding to humanitarian needs, as an integral part of their identity. Volunteering can present individuals with an opportunity for identity formation and the expression of values (Grönlund 2011). The importance of moral values to humanitarian workers' identity increases with time spent in aid work (Reimer et al. 2012). Denial has been recognised as a coping mechanism in challenging circumstances to avoid distress and minimise psychosocial costs (Boyraz et al. 2016; Friedrichs 2014; Vos and de Haes 2007). This suggests the salience of their humanitarian identity, and it being threatened due to loss of the in-group, may have led workers to engage in denial about their return.

Struggling with a threatened identity, participants aimed to sustain in-group belonging by (3b) 're-creation of the social setting', the second subordinate theme. Interestingly, this appears to contrast aid workers' inability to fulfil the group's identity prototype discussed in 'going to the limit', where belonging seemingly depends on the ability to take humanitarian action. This suggests outside the aid work setting the identity prototype of the humanitarian group changes, now enabling participants to sustain their belonging with the group. Here, being a member of the in-group is no longer reliant on the ability to take humanitarian action. Rather, group membership seems to consist of having returned to the UK following humanitarian work. Participants understood their re-creation of the social context of Northern France as a way to address the isolation experienced upon returning.

Whilst previous research considers the importance of peer support in tackling social isolation upon re-entry (McCormack et al. 2009), participants' re-creation of the humanitarian in-group is unique to the present research. Whilst the causes are unclear, different sample characteristics may contribute. A severe sense of social isolation was experienced by aid workers in McCormack and Joseph's (2013) and McCormack et al.'s (2009) research. Participants had a mean age of 53.3 years and worked recurrently in humanitarian settings, returning home to children, marriages and relationships between missions. In contrast, the mean age for the present research is about 27 years, an age category where identity is less stable than at 50 years of age (Fadjukoff et al. 2016). Furthermore, participants had not previously worked in humanitarian aid and did not expect to return to the field in the near future. Finally, none reflected on comparable family and relationship commitments at home. Whilst sample sizes are small and unrepresentative, the question arises whether having a more fluid identity, less defined commitments and responsibilities in the UK and seeing humanitarian work as a unique experience led participants to draw more strongly on the humanitarian in-group upon their return.

The third subordinate theme (3c) 'moral superiority' discusses participants' perception that their former ingroups (i.e. their social groups in the UK) have become their out-groups, defined by inferior moral values. This may be an attempt to sustain their belonging to the humanitarian in-group by accentuating similarities with the in-group and dissimilarities with the out-group, as described in SCT (Hogg and Terry 2000; Hogg et al. 1995). Hogg et al. (1995) suggest the in-group should compare favourably to the out-group to protect self-esteem, which may explain the focus on moral values. Whilst participants still share similarities with the out-group, moral differences have become the focus, leading to outgroup categorisation. Moral values thus anchor participants to their humanitarian in-group.

The moral superiority experienced by participants stands in a stark contrast to the moral doubt humanitarian workers described as part of McCormack and Joseph's (2013) research. Here, upon re-entry, aid 
workers lost their self-respect, doubted their own morality and actions taken in humanitarian work. Providing assistance in complex, extreme settings, including genocide, they had been unable to save lives. Therefore, their role fulfilment as humanitarian workers and their premission moral values were challenged. In contrast, participants of the current research were largely able to provide assistance in a less extreme, yet still complex setting. Thus, the nature of the humanitarian work may account for differences between re-entry processes.

Additionally, in understanding moral demarcation, the socio-political context of aid workers' lives should be considered. Participants in McCormack and Joseph's (2013) research reflected on colleagues, family and friends outside the humanitarian setting as lacking knowledge of the situations they worked in. Whilst the study does not identify their home countries, places of work suggest they worked far from home. Participants in the current research worked comparatively close and accessible to their home country, in a context present in media and politics. Thus, they may have been more likely to expect humanitarian acts from their home social setting, which shared knowledge of the situation, the lack thereof leading to feelings of moral superiority.

Finally, (4) 'Redefining belonging and identity', the fourth superordinate theme, discusses how participants move forward in their lives after returning. Aid workers' need to redefine who they are and what group(s) they identify with has been noted in previous research (McCormack and Joseph 2013; McCormack et al. 2009; Wartenweiler and Eiroa-Orosa 2016). However, what this process looks like differs according to the particular context. Participants in this study reflected on integrating moral values into their lives in the UK through volunteering or work, activities which they can engage in alongside other aspects of daily life. This allowed a bridging of the gap between Northern France and their present lives. Some appeared to belong to more than one in-group, allowing them to accommodate different parts of their identity, or to extend the humanitarian ingroup to include features of their lives in the UK. Others found new in-groups that allowed space for their values, showing similarities to returning Christian humanitarian workers who entered social groups that confirmed their new identities (Wartenweiler and Eiroa-Orosa 2016). Overall, aid workers' development of belonging upon reentry in this study reflects the dynamic responsiveness of social identity to social context (Turner et al. 1994; Turner and Reynolds 2012).

Whilst the continued integration of values plays an important role in moving forward for aid workers in this and previous research (McCormack and Joseph 2013; McCormack et al. 2009), participants in this study were not able to hold on to all values upon re-entry. Moving forward necessitated letting go of some values and expectations, suggesting participants' lives in the UK do not provide enough opportunities to practice them. This contrasts with McCormack and Bamforth's (2019) research with workers who assisted during the Ebola crisis in Sierra Leone. They reconfirmed their values in humanitarian work and were able to carry this identity boost into their lives upon re-entry. The authors acknowledge this is a unique finding and suggest strong organisational support may have contributed to these experiences of re-entry. However, considerations of the context of aid workers' lived experience suggest this explanation may be reductionist. The humanitarian workers in McCormack and Bamforth's research worked under strict safety protocols, separated from their environment, local people and peers through protective suits. In contrast, participants in the present study lived in close-knit communities of humanitarian workers in Northern France, akin to the intimate social setting described in other research (Hunt 2010; McCormack et al. 2009).

Sussman (2000) critiques SIT for failing to consider the effect of long or on-going exposure to cross-cultural settings on identity. She suggests a process of accommodation and adaptation to the socio-cultural context individuals live and work in as underlying identity change. Here, adaptation of aid workers' identity to the humanitarian in-group and work setting disrupts re-entry into former in-groups. Sussman's model could explain differing success in maintaining moral values and identity upon re-entry. As McCormack and Bamforth's (2019) research was characterised by physical separation, participants were unlikely to undergo the same level of accommodation and adaptation. In comparison, participants in the present research experienced a deep immersion in the socio-cultural context, leading to a fracture of moral identity upon re-entry.

\section{Strengths and limitations}

This research gives insights into aid workers' lived experiences of belonging and identity in the transition from working in humanitarian aid to returning home. Building on the accounts of 10 participants, it was possible to identify commonalities, whilst maintaining the idiographic nature of the phenomenological approach (Reid et al. 2005). Whilst participants were interviewed in single sessions, which may be considered a limitation, data gathered was rich and in-depth, with commonalities across accounts. In line with the epistemological position of this research, findings are not intended to and cannot be generalised (Smith et al. 2009). The focus on individual lived experience implies traditional criteria for evaluating research are unsuitable for assessing this study (Smith et al. 2009). Thus, Yardley's (2000) framework 
for evaluating qualitative research with sensitivity to its aims and methods is used.

This research's sensitivity to context is demonstrated by the choice of an appropriate epistemological position and methodology, engagement with a wide range of empirical and theoretical literature and the analysis of findings with awareness of the socio-cultural and political context. The breadth and depth of data collection, and the researchers' openness to data, including unexpected findings, show the commitment and rigour underlying this study. Transparency and coherence are demonstrated by the researchers' consistent adherence to methodological underpinnings, and presentations of interpretations alongside data extracts. Finally, impact and importance are shown by the research's contribution of context-specific findings to the literature on the reentry of humanitarian workers. As the first psychological study to date to explore the experiences of aid workers who returned from Northern France to the UK, it gives insight into a recent and on-going situation, and creates psychological knowledge relevant to the current sociopolitical reality.

Nonetheless, there are inherent epistemological and methodological limitations to the phenomenological approach (Larkin et al. 2006). The co-creation of knowledge through interpretation by the researcher is susceptible to biases and presuppositions. To ensure sense-making reflected the lived experience participants, the lead researcher, who has lived experience of humanitarian work in Northern France, engaged in an in-depth reflexive process on her subject position. Furthermore, both researchers engaged in robust discussions of the analysis and made joint decisions on the final themes. In addition, research participants, as well as humanitarian workers with similar lived experience, reviewed the analysis and found it reflective of their experience.

\section{Future directions}

Future research should address how role clarity, expectations and professional background may affect retention of international humanitarian workers, and identity disruption in the re-entry process. Such research could be quantitative allowing comparison between NGOs. Furthermore, it should create an understanding of how peer support upon re-entry can facilitate or hinder aid workers' reintegration. Future research should examine organisational structures in recently founded NGOs intended to prepare humanitarian workers for their return home, and what support humanitarian workers in these settings find helpful. Additionally, future work should examine the experiences of humanitarian workers in comparable settings, working with recently founded NGOs located further from their homes (e.g. Greece). The role of socio-cultural accommodation and adaptation in the re-entry process should be addressed; methodologically, this could be done using participant observation in the field and upon return. Finally, aid workers' perceptions of the physical world and border spaces are an interesting area for future investigation.

\section{Implications and recommendations}

The current research suggests that recently established NGOs may be able to better support international humanitarian workers' return home by providing clear role definitions and protocols, which encourage a professional distance whilst working in the field. These could include guidance on boundaries with beneficiaries, regulations regarding time off and clarifications of what is and is not expected of aid workers. This could help to reduce identity disruption in the re-entry process. Moreover, it is recommended to consider the specific humanitarian setting aid workers operate in, as well as their socio-cultural and political context, as these affect the nature of re-entry challenges.

When addressing the experiences of international humanitarian workers who are part of recently established NGOs, it may be helpful, and reflective of their understandings, to treat their belonging and identity as a continuous process and an on-going challenge. Support from NGOs could reflect this, with pre-mission preparation (e.g. briefings on what to expect in the field) and on-going supervision and support during humanitarian assignments (e.g. addressing protocol adherence). Furthermore, it may be helpful to provide international humanitarian workers without prior experience of aid work with guidance on the re-entry process (e.g. information on what challenges may arise and suggestions on how to address them). As disruptions to identity and belonging in the re-entry process are strongly dependent on humanitarian workers' ability to carry moral values forward into their home lives, activities like volunteering may provide a bridge between their humanitarian identity and their lives post-mission for international humanitarian workers. Additionally, this could help to address social isolation upon re-entry.

\section{Conclusion}

With humanitarian needs rising globally, aid workers' ability to respond to disasters is of increasing importance. However, with a focus on saving lives and relieving suffering of beneficiaries, NGOs at times fail to support humanitarian workers in dealing with the consequences of their work upon returning home. This research explores how international aid workers make sense of their lived experiences of being active in humanitarian aid in Northern France and returning to the UK. It focuses specifically on individuals who worked in recently founded NGOs, without a prior professional background 
in humanitarian work. IPA provides a methodology that allows understanding of the development of aid workers' belonging and identity through the process of re-entry.

This research contributes a novel, context-specific understanding of identity and belonging in transition, relevant to today's socio-political reality. NGOs could assist aid workers' return by treating development of belonging and identity as an on-going process, and supporting them accordingly with briefings and supervision pre-, during and post-mission. Here, providing clear role definitions and protocols that encourage maintenance of professional boundaries during assignments is recommended. Furthermore, NGOs can support aid workers' re-entry by encouraging engagement with activities that allow carrying moral values into their lives post-mission. Future work should address the role of peer networks in the re-entry process, and the experiences of humanitarian workers in other settings. With the re-entry not only affecting aid workers' reintegration and wellbeing, but also their ability to return to the field, this is essential for NGOs' ability to respond to future humanitarian emergencies.

\section{Abbreviations}

AID: Altruistic identity disruption; IPA: Interpretative phenomenological analysis; MSF: Médecins Sans Frontières; NGO: Non-governmental organisation; OHCHR: Office of the United Nations High Commissioner for Human Rights; SCT: Self-categorisation theory; SIT: Social identity theory; UNHCR: United Nations High Commissioner for Refugees

\section{Acknowledgements}

We would like to thank the anonymous reviewers for their helpful comments.

\section{Authors' contributions}

EW collected, analysed and interpreted the datasets of the current study and prepared the manuscript for publication. KWS supervised the research, made substantial contributions to the conception and design of the study and revised the manuscript. Both authors read and approved the final manuscript.

\section{Funding}

The authors received no funding for this work.

\section{Availability of data and materials}

The datasets generated and/or analysed during the current study are available from the corresponding author on reasonable request.

\section{Competing interests}

The authors declare that they have no competing interests.

Received: 14 April 2020 Accepted: 19 February 2021

Published online: 01 March 2021

\section{References}

Agier M, Bouagga Y, Galisson M, Hanappe C, Pette M, Wannesson P (2019) The Jungle: Calais's camps and migrants. Polity Press, Cambridge

Amnesty International. (2019). Targeting solidarity: criminalisation and harassment of people defending refugee and migrant rights in Northern France. Retrieved from https://www.amnesty.org/download/Documents/EUR2103562 019ENGLISH.PDF

Boyraz G, Waits JB, Felix VA, Wynes DD (2016) Posttraumatic stress and physical health. J Loss Trauma 21(1):47-61. https://doi.org/10.1080/15325024.2014. 965978
Chouliaraki L (2013) The ironic spectator: solidarity in the age of posthumanitarianism. Polity Press, Cambridge

Davies T, Isakjee A, Dhesi S (2017) Violent inaction: the necropolitical experience of refugees in Europe. Antipode 49(5):1263-1284. https://doi.org/10.1111/a nti.12325

Dhesi S, Isakjee A, Davies T (2018) Public health in the Calais refugee camp: environment, health and exclusion. Critical Public Health 28(2):140-152. https://doi.org/10.1080/09581596.2017.1335860

Dubey R, Gunasekaran A, Altay N, Childe SJ, Papadopoulos T (2016) Understanding employee turnover in humanitarian organizations. Indust Commercial Train 48(4):208-214. https://doi.org/10.1108/ICT-10-2015-0067

Edie JM (1987) Edmund Husserl's Phenomenology. Bloomington: Indiana University Press.

Ehrenreich JH, Elliott TL (2004) Managing stress in humanitarian aid workers: A survey of humanitarian aid agencies' psychosocial training and support of staff. Peace Conflict 10(1):53-66. https://doi.org/10.1207/s15327949pac1001_4

Eriksson CB, Bjorck JP, Larson LC, Walling SM, Trice GA, Fawcett J et al (2009) Social support, organisational support, and religious support in relation to burnout in expatriate humanitarian aid workers. Mental Health, Religion Cult 12(7):671-686. https://doi.org/10.1080/13674670903029146

Eriksson CB, Kemp HV, Gorsuch R, Hoke S, Foy DW (2001) Trauma exposure and PTSD symptoms in international relief and development personnel. J Traumatic Stress 14(1):205-212. https://doi.org/10.1023/A:1007804119319

Fadjukoff P, Pulkkinen L, Kokko K (2016) Identity formation in adulthood: a longitudinal study from Age 27 to 50. Identity 16(1):8-23. https://doi.org/10.1 080/15283488.2015.1121820

Fechter AM (2012) The personal and the professional: aid workers' relationships and values in the development process. Third World Quarterly 33(8):13871404. https://doi.org/10.1080/01436597.2012.698104

Friedrichs J (2014) Useful lies: The twisted rationality of denial. Philosophical Psychol 27(2):212-234. https://doi.org/10.1080/09515089.2012.724354

Grönlund $\mathrm{H}$ (2011) Identity and volunteering intertwined: reflections on the values of young adults. Voluntas 22(4):852-874. https://doi.org/10.1007/s112 66-011-9184-6

Hearns A, Deeny P (2007) The value of support for aid workers in complex emergencies: a phenomenological study. Disaster Management and Response 5(2):28-35. https://doi.org/10.1016/j.dmr.2007.03.003

Heidegger M (1977) Gesamtausgabe Band 2: Sein und Zeit. Frankfurt am Main: Vittorio Klostermann.

Hogg MA, Terry DJ (2000) Social identity and self-categorization processes in organizational contexts. Acad Manag Rev 25(1):121-140. https://doi.org/10.1 093/qje/qjq002.51

Hogg MA, Terry DJ, White KM (1995) A tale of two theories : a critical comparison of identity theory with social identity theory. Soc Psychol Quart 58(4):255269. https://doi.org/10.1207/S15324834BASP2402_2

Human Rights Watch. (2017). "Like Living in Hell" police abuses against child and adult migrants in Calais. Retrieved from https://www.hrw.org/sites/default/ files/report_pdf/france0717_web_3.pdf

Hunt MR (2008) Ethics beyond borders: how health professionals experience ethics in humanitarian assistance and development work. Dev World Bioethics 8(2):59-69. https://doi.org/10.1111/j.1471-8847.2006.00153.x

Hunt MR (2010) Moral experience of Canadian Healthcare professionals in humanitarian work. Prehosp Disast Med 24(6):518-524. https://doi.org/10.101 7/S1049023X00007445

Husserl E (1970) The crisis of European sciences and transcendental phenomenology: an introduction to phenomenological philosophy. Evanston: Northwestern University Press.

Husserl E (1913) Ideen zu einer reinen Phänomenologie und phänomenologischen Philosophie. Erstes Buch. Allgemeine Einführung in die reine Phänomenologie. Halle an der Saale: Verlag von Max Niemeyer.

Jachens L, Houdmont J, Thomas R (2018) Work-related stress in a humanitarian context: a qualitative investigation. Disasters 42(4):619-634. https://doi.org/1 $0.1111 /$ disa. 12278

Jachens L, Houdmont J, Thomas R (2019) Effort-reward imbalance and burnout among humanitarian aid workers. Disasters 43(1):67-87 https://doi.org/1 $0.1111 /$ disa. 12288

Joint Ministerial Declaration. (2015). Managing migratory flows in Calais: joint ministerial declaration on UK/French co-operation. Retrieved from https://a ssets.publishing.service.gov.uk/government/uploads/system/uploads/atta chment_data/file/455162/Joint_declaration_20_August_2015.pdf 
Korff VP, Balbo N, Mills M, Heyse L, Wittek R (2015) The impact of humanitarian context conditions and individual characteristics on aid worker retention. Disasters 39(3):522-545. https://doi.org/10.1111/disa.12119

Langdridge D (2007) Phenomenological psychology: theory, research and method. Pearson Education Limited, Harlow

Larkin M, Watts S, Clifton E (2006) Giving voice and making sense in Interpretative Phenomenological Analysis. Qual Res Psychol 3(2):102-120. https://doi.org/10.1191/1478088706qp062oa

Lopez KA, Willis DG (2004) Descriptive versus interpretive phenomenology: Their contributions to nursing knowledge. Qual Health Res 14(5):726-735. https:// doi.org/10.1177/1049732304263638

McCormack L, Bamforth S (2019) Finding authenticity in an altruistic identity: the "lived" experience of health care humanitarians deployed to the 2014 Ebola crisis. Traumatology. https://doi.org/10.1037/trm0000171

McCormack L, Joseph S (2012) Postmission altruistic identity disruption questionnaire (PostAID/Q): preliminary development of a measure of responses following adverse humanitarian aid work. Traumatology 18(3):4148. https://doi.org/10.1177/1534765611430726

McCormack L, Joseph S (2013) Psychological growth in humanitarian aid personnel: Reintegrating with family and community following exposure to war and genocide. Commun Work Fam 16(2):147-163. https://doi.org/10.1 080/13668803.2012.735478

McCormack L, Joseph S, Hagger MS (2009) Sustaining a positive altruistic identity in humanitarian aid work: a qualitative case study. Traumatology 15(2):109118. https://doi.org/10.1177/1534765609332325

McCormack L, Orenstein A, Joseph S (2016) Postmission altruistic identity disruption questionnaire (PostAID/Q): Identifying humanitarian-related distress during the reintegration period following international humanitarian aid work. Traumatology 22(1):1-8. https://doi.org/10.1037/trm0000053

McGee D, Pelham J (2018) Politics at play: locating human rights, refugees and grassroots humanitarianism in the Calais Jungle. Leisure Stud 37(1):22-35. https://doi.org/10.1080/02614367.2017.1406979

MSF. (2016a). Refugee Crisis: MSF granted permission for new camp in northern France. Retrieved July 5, 2019, from https://www.msf.org.uk/article/refugeecrisis-msf-granted-permission-new-camp-northern-france

MSF. (2016b). Update on relocation of migrant camp in Dunkirk. Retrieved July 5, 2019, from https://www.msf.org/france-update-relocation-migrant-campdunkirk

Noon EJ (2018) Interpretative phenomenological analysis: an appropriate methodology for educational research? J Perspect Appl Acad Pract 6(1):7583. https://doi.org/10.14297/jpaap.v6i1.304

OHCHR. (2017). France must provide safe drinking water and sanitation for migrants in the "Calais Jungle", say UN rights experts. Retrieved July 5, 2019 from https://www.ohchr.org/EN/NewsEvents/Pages/DisplayNews.a spx?NewsID=22240\&LangID $=\mathrm{E}$

OHCHR. (2018). France urged by UN experts to take effective measures to bring water and sanitation services to migrants. Retrieved July 5, 2019, from https://www.ohchr.org/EN/NewsEvents/Pages/DisplayNews.aspx?NewsID=22 917

Reid K, Flowers P, Larkin M (2005) Exploring lived experience. Psychologist 18(1): 20-23

Reimer KS, Young C, Birath B, Spezio ML, Peterson G, van Slyke J, Brown WS (2012) Maturity is explicit: Self-importance of traits in humanitarian moral identity. J Posit Psychol 7(1):36-44. https://doi.org/10.1080/17439760.2011.62 6789

Reis C, Bernath T (2016) Becoming an international humanitarian aid worker. Elsevier, Oxford

Sandri E (2018) 'Volunteer humanitarianism': Volunteers and humanitarian aid in the jungle refugee camp of Calais. J Ethnic Migration Stud 44(1):65-80. https://doi.org/10.1080/1369183X.2017.1352467

Sanyal D (2017) Calais's "Jungle": Refugees, biopolitics, and the arts. Representations 139(1):1-33. https://doi.org/10.1525/rep.2017.139.1.1

Selby S, Moulding N, Clark S, Jones A, Braunack-Mayer A, Beilby J (2009) Back Home: A Qualitative Study Exploring Re-Entering Cross-Cultural Missionary Aid Workers' Loss and Grief. OMEGA J Death Dying 59(1):19-38. https://doi. org/10.2190/OM.59.1.b

Smith JA (1996) Beyond the divide between cognition and discourse: using interpretative phenomenological analysis in health psychology. Psychol Health 11(2):261-271. https://doi.org/10.1080/08870449608400256
Smith JA, Osborn M (2013) Interpretative phenomenological analyis. In: Smith JA (ed) Qualitative Psychology A Practical Guide to Research Methods. SAGE Publications Ltd., London, pp 25-52

Snelling M (2018) The impact of emergency aid work on personal relationships: a psychodynamic study. J Int Humanitarian Action 3(1):3-14. https://doi.org/1 0.1186/s41018-018-0042-7

Strohmeier H, Scholte WF (2015) Trauma-related mental health problems among national humanitarian staff: A systematic review of the literature. Eur J Psychotraumatol 6(1):1-16. https://doi.org/10.3402/ejpt.v6.28541

Sussman NM (2000) The dynamic nature of cultural identity throughout cultural transitions: why home is not so sweet. Personality and Social Psychology Review 4(4):355-373. https://doi.org/10.1207/S15327957PSPR0404_5

Smith JA, Flowers P, Larkin M (2009) Interpretative Phenomenological Analysis Theory, Method and Research. London: SAGE Publications Ltd.

Szkudlarek B (2010) Reentry - A review of the literature. Int J Intercultural Relations 34(1):1-21. https://doi.org/10.1016/J.IJINTREL.2009.06.006

Tajfel H (1978) Differentiation between social groups: studies in the social psychology of intergroup relations. Academic Press, London

Tajfel H (1982) Social psychology of intergroup relations. Annual Review of Psychology 33(1):1-39. Retrieved from. https://doi.org/10.1146/annurev.ps.33. 020182.000245

Tajfel H, Turner J (1979) An integrative theory of intergroup conflict. In: Austin WG, Worchel S (eds) The social psychology of intergroup relations. BrooksCole Publishing, Monterey, pp 33-47

Turner JC (1975) Social comparison and social identity: Some prospects for intergroup behavior. Eur J Soc Psychol 5(1):5-34. https://doi.org/10.1002/ ejsp.2420050102

Turner JC, Brown RJ (1978) Social status, cognitive alternatives and intergroup relations. In: Tajfel H (ed) Differentiation between social groups: Studies in the social psychology of intergroup relations. Academic Press, London, pp 201-234

Turner JC, Oakes PJ, Haslam SA, McGarty C (1994) Self and collective: cognition and social context. Pers Soc Psychol Bull 20(5):454-463. https://doi.org/10.11 $77 / 0146167294205002$

Turner JC, Reynolds KJ (2012) Self-categorization theory. In: Van Lange PAM, Kruglanski AW, Higgins ET (eds) Handbook of Theories of Social Psychology. SAGE Publications Ltd. Retrieved from, London, pp 399-417. https://doi.org/1 0.4135/9781446249222.n46

UNHCR. (2016). UNHCR concerned about conditions in Calais and Dunkerque. Retrieved July 5, 2019, from https://www.unhcr.org/56b4ac916.html

UNHCR. (2018). Global Report 2017. Retrieved from http://reporting.unhcr.org/ sites/default/files/gr2017/pdf/GR2017_English_Full_lowres.pdf

Vos MS, de Haes JCJM (2007) Critical incidents in contact with healthcare reflecting the needs of women with breast cancer. Psycho-Oncology 16(1): 12-25. https://doi.org/10.1002/pon.1051

Wartenweiler T, Eiroa-Orosa FJ (2016) Effects of spiritual change on the re-entry adjustment of christian young adult humanitarian workers. J Pastoral Care Counseling 70(3):176-185. https://doi.org/10.1177/1542305016655177

Xiao YJ, van Bavel JJ (2012) See your friends close and your enemies closer: social identity and identity threat shape the representation of physical distance. Pers Soc Psychol Bull 38(7):959-972. https://doi.org/10.1177/01461 67212442228

Yardley L (2000) Dilemmas in Qualitative Health Reserach. Psychol Health 15(1): 215-228. https://doi.org/10.1080/08870440008400302

\section{Publisher's Note}

Springer Nature remains neutral with regard to jurisdictional claims in published maps and institutional affiliations. 